\title{
Seasonal climate patterns and their influence on calibration of the Hargreaves Samani Equation
}

\author{
S. Shahidian ${ }^{1,2}$, R. P. Serralheiro, ${ }^{1,2}$, J. R. Serrano ${ }^{1,2}$, J. L. Teixeira ${ }^{3}$ \\ ${ }^{1}$ Departmento de Engenharia Rural, Universidade de Évora, Évora, Portugal \\ Email: shakib@uevora.pt \\ ${ }^{2}$ ICAAM- Instituto de Ciências Agrárias e Ambientais Mediterrânicas, Évora, Portugal \\ ${ }^{3}$ ISA_Insituto Superior de Agronomia, Universidade Técnica de Lisboa, Lisboa, Portugal
}

Citation: Shahidian S., Serralheiro, R.P., Serrano J.R., Teixeira, J.L.,2014. Seasonal

climate patterns and their influence on calibration of the Hargreaves Samani Equation. Hydrological Sciences Journal, 5 ( )

\begin{abstract}
The purpose of this work is to study the annual patterns in climate parameters and to evaluate how these influence the quality of reference evapotranspiration (ETo) estimates obtained from the Hargreaves Samani (HS) equation, since the method only uses the measured temperature parameter directly. To conclude, the work evaluates how these patterns can be used to improve the HS ETo estimates. Ten year moving averages from a set of CIMIS stations were used to evaluate the relations between solar radiation (Rs), temperature (T) and ETo. The results indicate that $\mathrm{T}$ treads behind solar radiation and its value peaks some 25 days later. As a result, the main irrigation season in the Mediterranean climate (May 1-September 30) can be divided into three phases: increasing Rs and T; decreasing Rs with increasing T; decreasing Rs and T. Non univocal annual cycles were observed between Rs and T, ETo and Rs, and ETo and T. These annual patterns result in important seasonal changes in the ratio between the Hargreaves Samani and Penman Monteith (FAO PM) ETo estimates. The changes are particularly important during the irrigation season, where the FAO PM initially calculates greater ETo values than the HS methodology and from the end of May to early September, the HS equation overestimates the ETo values. The total overestimation by the HS equation during this period is $17 \mathrm{~mm}$, or $3 \%$. These patterns obtained from 2000-2009 data were used to calibrate and improve HS ETo estimates at new sites during the 2010-2011 period. Calibration based on the proposed seasonal region-wide FAO PM/ HS ETo ratios improved both the bias, which decreased from 0.40 to $0.36 \mathrm{~mm} \mathrm{day}^{-1}$, and $\mathrm{r}^{2}$, which increased from 0.67 to 0.87 of the ETo estimates during the irrigation season. The proposed methodology can be easily applied to other regions, even when the existing weather stations are sparse.
\end{abstract}

Key words Hargreaves Samani; evapotranspiration; climate; irrigation

\section{INTRODUCTION}

The United Nations Food and Agriculture Organization (FAO) has adopted the Penman-Monteith method (PM) as a global standard to estimate grass reference ETo, with details presented in the Irrigation and Drainage Paper no. 56 (Allen et al. 1998).

The limited number of reliable and well-maintained weather stations and the time and cost involved in daily acquisition and processing of the necessary meteorological data largely limit the generalized application of the PM methodology in irrigation scheduling. There are also concerns about the accuracy of the observed meteorological parameters, since some instruments, specifically pyranometers and hygrometers, are often subject to stability errors (Henggeler et al. 1996). Droogers 